\title{
Study of physisorption of volatile anesthetics on phospholipid monolayers using a highly sensitive quartz crystal microbalance (HS-QCM)
}

\author{
Yasushi Yamamoto ${ }^{1^{*}}$, Zameer Shervani ${ }^{2^{*}}$, Takatsugu Shimoaki ${ }^{1}$, Daisuke Yoshida ${ }^{1}$, Takashi \\ Yokoyama $^{1}$, Tadayoshi Yoshida ${ }^{1}$, Keijiro Taga $^{1}$, Hiroshi Kamaya ${ }^{3}$, Issaku Ueda ${ }^{3}$

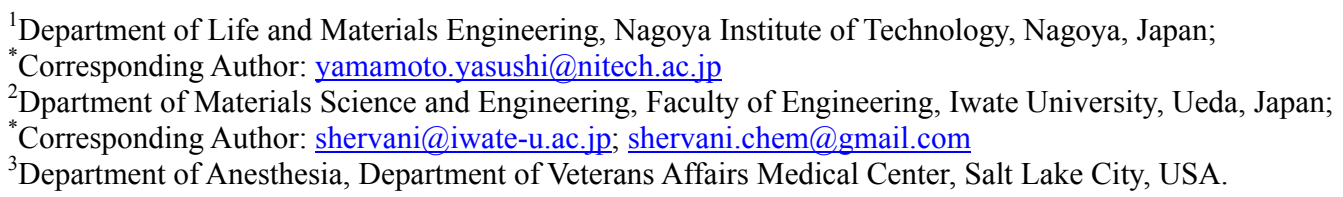

Received 10 December 2010; revised 5 January 2011; accepted 20 January 2011.

\begin{abstract}
We have investigated the interactions between phospholipid monolayers and volatile anesthatics. Two monolayers (dihexadecyl phosphate (DHP) and dipalmitoyl phosphatidyl choline (DPPC) and two anesthetics (halothane and enflurane) were used to observe these interactions using a highly sensitive quartz crystal microbalance (HS-QCM). The concentration of each anesthetic in aqueous solution was kept at $4 \mathrm{mM}$. The frequency of QCM showed no change when halothane was added to the DHP monolayer, however, it responded and decreased when interaction occurred with DPPC monolayer. In case of enflurane addition the frequency decreased in both the monolayers of DHP and DPPC. The frequency change followed the following order of monolayer-anesthetic interactions: DHP-halothane < DPPC-halothane $<$ DHP-enflurane < DPPC-enflurane. These results showed that the response of anesthetics to the monolayers i.e., the physisorption not only depends on the anesthetic structure, the type of anesthetic hydrate formed, but also the hydrophilic polar group structure of the mono-layer or the monolayer/water interface had an important role in physisorption.
\end{abstract}

Keywords: Physisorption; Phospholipid Monolayers; Quartz Crystal Microbalance (QCM); Anesthetic Hydrate; Monolayer-Water Interface

\section{INTRODUCTION}

Intermolecular interactions: hydrogen bonding, hy- drophobic interaction, van der Waals interaction play an important role in various cellular functions such as the construction of tertiary structures of protein, the hybridization of DNA, the molecular recognition of membranes, and the transportation of nutrients and medicines [1-3]. The phenomenon of the interaction between a biomembrane and an anesthetic is also considered to be in the category of the above mentioned interactions. Anesthetics have structures containing moieties: hydroxyl, ether, chloroform, etc. apart from known halothane and enflurance used in this work. Anesthetic phenomenon occurs at high body concentrations in the order of millimol (mM); the effect of anesthetic is reversibility depending on the medication concentration $[4,5]$. The anesthetic potency is also temperature dependent [6-8]. Therefore the mechanism of anesthesia has been regarded as "physisorption phenomenon" in which an anesthetic aggregation acts indirectly at the interface of biomembrane-body fluid [9].

A quartz crystal microbalance (QCM) is a powerful method to investigate the above interfacial phenomenon occurring in liquid phases. QCM can detect the mass of substances adsorbed onto a quartz crystal oscillator (QCO) in a very minute amount up to the order of nanograms [10]. Many studies on chemisorption processes such as the oxidation and redox processes on a modified self-assembled monolayers $[11,12]$, metal ion binding to langmuir monolayers $[13,14]$, and molecular recognition of DNA strands and lipids [15-18] have been reported over the last several decades. While there are fewer reports on the investigation of physisorption processes because of the high QCM sensitivity that restricts the use of the method. Ebara et al. [19] have investigated the complementary guest pyridine compounds and acid 
binding process involving hydrogen bonding onto various cyanurate lipid monolayers formed at air/water interface using a $27 \mathrm{MHz}$ QCM assembly and suggested that the microenvironment near the lipid surface in a living body is similar to hydrophobic organic medium. Sato et al. [20] have investigated the interaction between aminopurinethiol monolayers and oligonucleotides using a high sensitively improved $5 \mathrm{MHz}$ QCM device that had stability range $\pm 0.3 \mathrm{~Hz}$. The authors claimed, based on the data and results obtained from highly sensitive QCM apparatus, that the hydrogen bonding interactions between the monolayers and complementary nucleic acid bases dissolved in a solution could be detected by their devices.

In this communication, we report physisorption interactions between two phospholipid monolayers DHP and DPPC and two anesthetics halothane and enflurane using a highly sensitively improved $6 \mathrm{MHz}$ QCM device with a stability range $\pm 0.5 \mathrm{~Hz}$ for $>12 \mathrm{~h}$. A quartz crystal oscillator (QCO) was attached $[21,22]$ horizontally to the monolayer formed at water surface. The artificially prepared phospholipid monolayer proved to be a good model that allowed to study a real living phenomenon including anesthesia. The investigation of a model physisorption in monolayer-anesthetic interactions using a QCM yielded important information for the elucidation of anesthesia mechanism.

\section{MATERIALS, METHODS, AND APPARATUS}

Dihexadecyl phosphate (DHP > 99\%) and dipalmitoyl phosphatidyl choline (DPPC; 97\%), which were used as the model membrane compounds were purchased from Sigma-Aldrich Corp. (St. Louis, USA) and Fluka Chemical Corp. Inc. (Seelze, Germany), respectively. Both the chemicals for membrane preparation were used without further purification. Halothane (2-bromo2-chloro-1,1,1-trifluoroethane $>99 \%$ ) and enflurane ((RS)-2-chloro-1,1,2-trifluoroethyl difluoromethyl ether $>99 \%$ ) which were used as volatile anesthetic were also purchased from Sigma-Aldrich Corp. (St. Louis, USA) and Abbott Japan Corp. Ltd. (Tokyo, Japan), respectively.

Figure 1 shows the molecular structures of monolayer forming compounds and anesthetics used in this work. Ultra pure water with conductance of $<0.07 \mathrm{~S} / \mathrm{cm}$ was obtained from a Super Water Purifying System (WL-21P; Yamato Scientific Corp. Ltd., Tokyo, Japan); the water was boiled for $10 \mathrm{~min}$ and subsequently cooled to room temperature $[21,22]$. The concentration of each anesthetic in aqueous solutions was $4 \mathrm{mM}$. A $1 \mathrm{mM}$ solution of each DHP and DPPC in chloroform (99\%, Wako Pure Chemical Industries Ltd., Osaka, Japan) were spread on

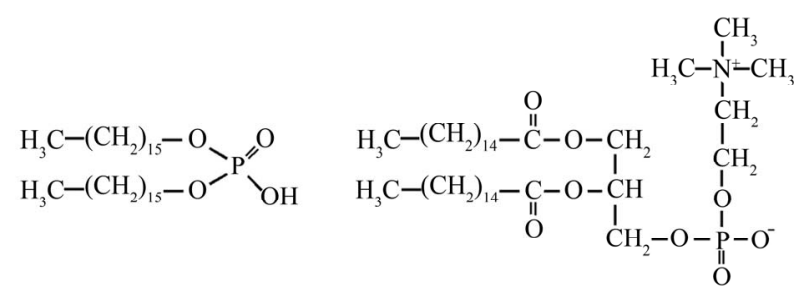

DHP

DPPC<smiles>FC(F)(Cl)C(Br)Br</smiles><smiles>FC(F)O[Te]C(F)Cl</smiles>

halothane enflurane

Figure 1. Molecular structures of phospholipids and anesthetics.

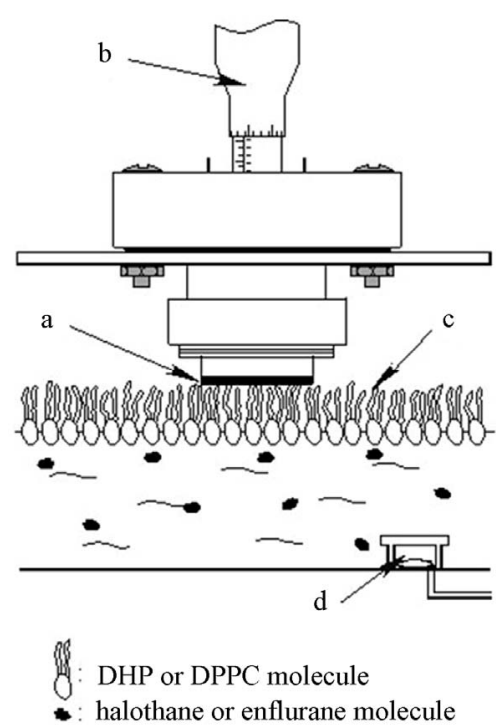

Figure 2. Schematic diagram of the central part of the QCM apparatus: a) QCO; b) micrometer; c) DHP or DPPC monolayer; d) small poly (tetrafluoroethylene) vessel and stirring bar.

a purified water surface by spreading method using a 1001 microsyringe (Ge-0583-04; Hamilton Corp., Nevada, USA). Surface tension was measured using Wilhelmy method by a surface tensiometer (CBVP-A3; Kyowa Interface Science Corp., Ltd., Saitama, Japan). We confirmed Langmuir type DHP and DPPC monolayers were formed spontaneously on the water surface $[21,22]$. The details of the experimental apparatus for HS-QCM measurement have been reported in earlier publications [21,22]. Figure 2 shows a schematic diagram of the central part of the HS-QCM apparatus. After a $6 \mathrm{MHz}$ QCO (Hokuto Denko Corp., Tokyo, Japan) Figure 2(a) was attached horizontally using a micrometer (Figure 2(b)) to the DHP or DPPC monolayer (Figure 2(c)) with the surface pressures of $15 \mathrm{mN} / \mathrm{m}$ (DHP) 
and $38 \mathrm{mN} / \mathrm{m}$ (DPPC) [21,22]; anesthetics halothane and enflurane were dissolved into the water phase (Figure 2(d)). Using above explained assembly we observed the change in the QCO frequency that was in contact with the DHP or DPPC monolayer. After the addition of halothane and enflurane $(4 \mathrm{mM})$, the stability of the QCO frequency before the addition of halothane and enflurane was maintained within $\pm 0.5 \mathrm{~Hz}$ for longer than 12 hours $[21,22]$. Each measurement was carried out thrice for maintaining reproducibility in the work. The experimental error was within $\pm 0.5 \mathrm{~Hz}$ range. A frequency change $(\Delta f)$ of $1 \mathrm{~Hz}$ on the $6 \mathrm{MHz}$ QCO corresponded to a mass change $(\Delta m) 12.2 \mathrm{ng} / \mathrm{cm} 2$ [10]. All experiments were conducted at temperature $26.00^{\circ} \mathrm{C} \pm 0.01^{\circ} \mathrm{C}$.

\section{RESULTS}

\subsection{HS-QCM Measurements}

Figure 3 shows the typical time course of the QCO frequency that was in contact with the DHP or DPPC monolayer after the addition of halothane and enflurane.

The concentration of each anesthetic dissolved in an aqueous solution was $4 \mathrm{mM}$. The horizontal axis represents time (h). The vertical axis represents the frequency change $(\Delta f)(\mathrm{Hz})$ based on the resonance frequency before the addition of each anesthetic. No change in the frequency was observed for 4 hours on the addition of halothane to the DHP monolayer. While the frequency decreased gradually until it approached an equilibrium state to the DPPC monolayer (Figure 3 (b)). The value of $\Delta f$ in this case was $-1.4 \mathrm{~Hz}$ and physisorbed mass $(\Delta m)$ was $17.1 \mathrm{ng} / \mathrm{cm}^{2}$. Because the stirring bar was stirred gently in the water $(1 \mathrm{r} / \mathrm{s})$, the delayed response $>1 \mathrm{~h}$ is due to the time required for diffusion of the halothane molecules from the bulk solution to the DPPC monolayer/water interface $[13,15,16,21]$. A similar tendency of frequency decrease was observed on the addition of enflurane to the DHP and DPPC monolayers (Figures 3(c) and (d)), respectively). The $\Delta f$ values were $-2.1 \mathrm{~Hz}$ for the DHP monolayer while observed $\Delta m$ was $25.6 \mathrm{ng} / \mathrm{cm}^{2}$ and -3.1 $\mathrm{Hz}$ for the DPPC monolayer and $\Delta m: 37.8 \mathrm{ng} / \mathrm{cm}^{2}$. Our recent concentration-dependence study with regard to the interaction of enflurane with the DPPC monolayer revealed that $\Delta f$ of $-3.1 \mathrm{~Hz}$ at $4 \mathrm{mM}$ is nearly to the initial saturation value that corresponds to the amount of semi-saturated physisorption layer of enflurane hydrates [23]. Table 1 summarizes the $\Delta f$ and $\Delta m$ values of the DHP and DPPC monolayers interacting with halothane and enflurance anesthatics.

\subsection{Surface Tension Measurement}

Figure 4 shows the surface pressure vs molecular area DHP and DPPC monolayers form a LE (liquid expanded)

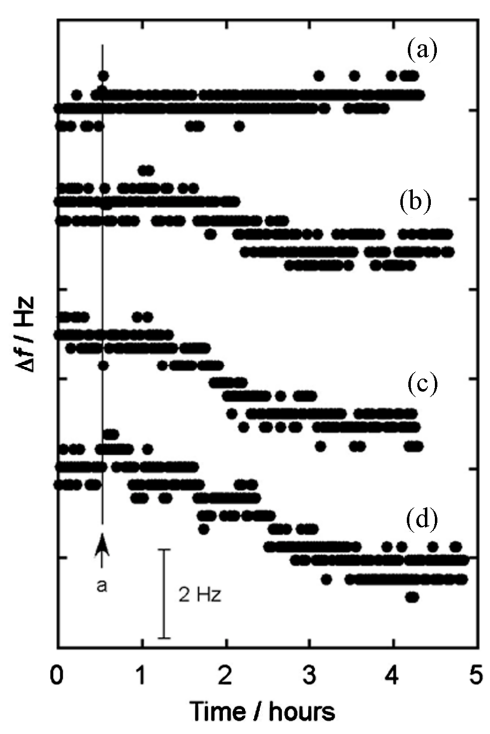

Figure 3. Typical time course of the resonance frequency of QCO $(\Delta f)$ which was in contact with DHP or DPPC monolayer after the addition of halothane and enflurane at point shown by arrow a: (a) DHP monolayer vs halothane; (b) DPPC monolayer vs halothane; (c) DHP monolayer vs enflurane; (d) DPPC monolayer vs enflurane.

Table 1. Changes of resonance frequency of QCO $(f(\mathrm{~Hz}))$ and mass change $(m(\mathrm{ng} / \mathrm{cm} 2))$ which was in contact with the DHP and DPPC monolayers after the addition of halothane and enflurane at a fixed $4 \mathrm{mM}$ concentration.

\begin{tabular}{lcrrr}
\hline & \multicolumn{2}{c}{ DHP } & \multicolumn{2}{c}{ DPPC } \\
\cline { 2 - 5 } & $f(\mathrm{~Hz})$ & $m\left(\mathrm{ng} / \mathrm{cm}^{2}\right)$ & \multicolumn{1}{c}{$f(\mathrm{~Hz})$} & $m\left(\mathrm{ng} / \mathrm{cm}^{2}\right)$ \\
\hline Halothane & $0.0 \pm 0.2$ & 0.0 & $-1.4 \pm 0.5$ & 17.1 \\
Enflurance & $-2.1 \pm 0.5$ & 25.6 & $-3.1 \pm 0.5$ & 37.8 \\
\hline
\end{tabular}

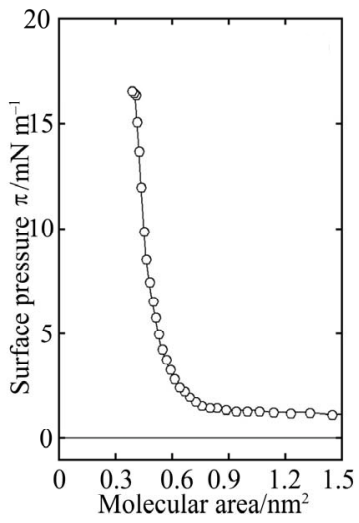

(a)

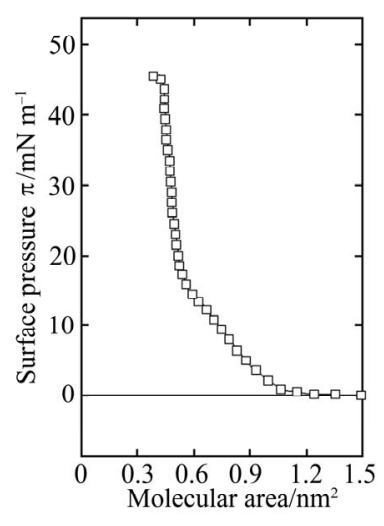

(b)
Figure 4. Surface pressure versus molecular area $(\Delta-\mathrm{A})$ isotherm of (a) DHP monolayer; (b) DPPC monolayer.

$(\Delta-A)$ isotherm for DHP (Figure 4(a)) and DPPC monolayers (Figure 4(b)) obtained using the spreading method $[21,22]$ at $26.0^{\circ} \mathrm{C}$. It is reported that both 
state at low surface pressures and a LC (liquid condensed) state at high surface pressures [24]. The LE-LC transition occurs at $8 \mathrm{mN} / \mathrm{m}$ for DHP monolayer and 10 $\mathrm{mN} / \mathrm{m}$ for DPPC monolayer, respectively. Our results of spreading method conducted in this work also showed the LE-LC transitions at the same values of surface tension. However, the shapes of the curves (Figure 4) for DHP and DPPC monolayers were a little different compared to those reported previously [24].

\section{DISCUSSION}

\subsection{Halothane and Enflurane Structure and Properties as Anesthetics}

Halothane and enflurane are generally used as inhalation anesthetic. A halothane molecule comprises fluorine, chlorine, and bromine atoms, while an enflurane molecule has fluorine and oxygen (Figure 1). The difference in their compositions can be noticed in their molecular properties such as hydrophobicity and solubility [4,25]. A characteristic common to both the anesthetics is that when dissolved in an aqueous solution, water molecules surround the anesthetic molecules and form a hydration cluster (hydrophobic hydration) [25,26]. At $4 \mathrm{mM}$ of anesthetic concentration, every anesthetic molecule is surrounded by water molecules to form monomer water hydrates [9,26,27].

\subsection{DHP and DPPC Monolayers}

The surface tension measurements revealed that the molecular areas of DHP was $0.54 \pm 0.03 \mathrm{~nm}^{2} /$ molecule and surface pressure was $16 \mathrm{mN} / \mathrm{m}$. While for DPPC surface pressure was $38 \mathrm{mN} / \mathrm{m}$ and molecular area was $0.65 \pm 0.05 \mathrm{~nm}^{2} /$ molecule $[21,22]$. The DHP and DPPC monolayers in this experiment were as close as to their maximum packing. However, the molecular areas of these monolayers were $30 \%$ larger to those of condensed monolayers $\left(0.42 \mathrm{~nm}^{2} /\right.$ molecule for DHP and 0.47 $\mathrm{nm}^{2} /$ molecule for DPPC) considering compressing method [24,28]. That is because each monolayer in our measurements was in a "semi-expanded state" and had a "fluid-rich" structure with interfacially restricted water. The difference in the molecular areas of DHP $\left(0.54 \mathrm{~nm}^{2}\right)$ and DPPC $\left(0.65 \mathrm{~nm}^{2}\right)$ monolayers, despite both DHP and DPPC molecules possessing two hydrophobic alkyl chains, is due to the degree of interaction between the hydrophilic groups and the water molecules [21,29]. The hydrophilic group of DHP is $(-\mathrm{O}-)_{2}-\mathrm{PO}(\mathrm{OH})$, a typical semi-nonionic headgroup, whereas, DPPC group is, $\left(-(\mathrm{CO})-\mathrm{O}-\mathrm{CH}_{2}-(\mathrm{CO}) \mathrm{O}-\right)-\mathrm{CH}-\mathrm{CH}_{2}-\mathrm{O}-\mathrm{POO}^{-}-\mathrm{O}-\left(\mathrm{CH}_{2}\right)_{2}-$ $\mathrm{N}^{+}\left(\mathrm{CH}_{3}\right)_{3}$, a typical zwitter ionic headgroup (Figure 1) [24]. The hydrophilic groups of DHP form a smooth hydrogen bond network of interfacially restricted water with free water molecules. In contrast, the restricted water formed on the DPPC/water interface is more complex than the one formed on the DHP/water interface [29,30]. The former's head is complicated and larger than that of latter. In both the monolayers formed by DHP and DPPC, water molecules play an important role in maintaining the structure of the amphiphilic monolayer formed on water surface as well as in the interactions between the hydrophobic moieties of the monolayer [28,31]. In other words, the hydrophilic groups of the DHP and DPPC molecules and water molecules structured themselves in the most comfortable arrangement which is different from the behavior exhibited by compression method monolayers [24]. Therefore, the possibility exists that halothane and enflurane hydrates can physisorb on such a fluidic monolayer/water interface [32].

\subsection{Monolayer-Anesthetic Interaction}

Yoshino et al. [27] reported that the restricted water in a water-in-oil emulsion changed to free water by the action of enflurane hydrates. The reaction of halothane hydrates with a sodium dodecyl sulfate (SDS) micelle/water interface has also been reported [33]. In case of halothane solubilization, the $-\mathrm{CF}_{3}$ ends of the anesthetic hydrates localized at the interface, whereas the $-\mathrm{CHClBr}$ ends remained dissolved in the water phase. The authors also further reported that when enflurane hydrates interacted with the above SDS micelle/water interface, the molecular axis orientation of enflurane molecule was parallel to the interface [34]. These reports indicate that anesthetics hydrates interact with the interfacially restricted water formed at the membrane/water interface and do not penetrate into the membrane's lipid core. Furthermore the physisorption potency of enflurane hydrate physisorbed on the restricted water is higher than that of halothane hydrate being a larger molecule. In other words, the enflurane hydrate physisorbs on the restricted water more easily than the halothane hydrate because the physisorption capable sites in halothane hydrate are only the $-\mathrm{CF}_{3}$ end groups, whereas that of the enflurane hydrate includes all the sites of enflurane molecular axis. The molecule of enflurane has one hydrophilic oxygen atom, which is different from the hydrophobic molecular structure of halothane. This "semi-hydrophobic" property of enflurane increases the strength of the interaction between enflurane hydrates and the restricted water. Based on our results and those of above mentioned references, the mechanism of the interaction of halothane and enflurane with the DHP and DPPC monolayers can be explained on the model described in Figure 5 and the results have been shown in Table 1. Halothane hydrates 


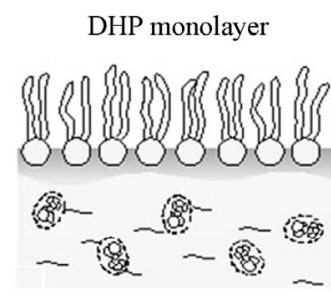

(a) Halothane hydrate

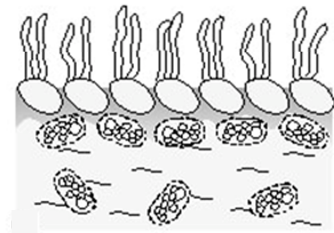

(d)

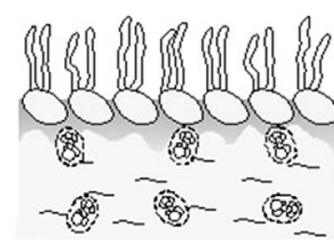

(b)

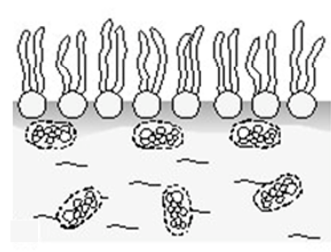

(c)
Figure 5. Schematic illustration of the interactions between the DHP or DPPC monolayer and halothane or enflurane hydrate: (a) DHP monolayer vs halothane hydrate; (b) DPPC monolayer vs halothane hydrate; (c) DHP monolayer vs enflurane hydrate; (d) DPPC monolayer vs enflurane hydrate.

with less physisorption capable sites $-\mathrm{CF}_{3}$ rarely physisorb on a smooth (small head group) DHP monolayer/water interface. DPPC has larger head group than DHP molecule therefore monolayer/water interface in bulkier and more spacious in former than latter. Thus more physisorption sites (acceptors) exist at the interface formed by DPPC than DHP. As a result halothane hydrates physisorb on physisorption sites at the DPPC monolayer/water interface and those were detected by sensitive QCM apparatus. The results of $\Delta f(\mathrm{~Hz})$ and $\Delta m$ $\left(\mathrm{ng} / \mathrm{cm}^{2}\right)$ have been compared in Table 1. Enflurane hydrates, on the other hand, whose molecular axis are physisorption capable due to large size anethetic can physisorb (Table 1) at even the smooth and smaller DHP monolayer/water interface. Many enflurane hydrates physisorb easily on the DPPC monolayer/water interface and reach to a semi saturated physisorption state [23] because of the existence of more physisorption sites or acceptors (Figure 5(d)).

In an unpublished but concluded study [35], we have found that enflurane $(4 \mathrm{mM})$ does not physisorb at $n$-hexadecanol monolayer/water interface. The above monolayer was the condensed and solid with very small molecular area $0.20 \mathrm{~nm}^{2}$ [36] even though it was formed by the spreading method. The interfacially restricted water in this system was stable and had poor fluidity. The effect of condensed or solid monolayer on physisorption was also noticed in the study of enflurane (4 $\mathrm{mM}$ ) physisorbtion on DPPC-cholesterol mixed monolayer/water interface when DPPC-to-cholesterol ratio was $8: 2$. The phisisorption frequency and volume were
$\Delta f=-1.8 \mathrm{~Hz}$ and $\Delta m=21.9 \mathrm{ng} / \mathrm{cm}^{2}$, respectively. This mixed monolayer condensed partially by the condensation effect of cholesterol which had molecular area $0.48 \mathrm{~nm}^{2}$. In this mixed monolayer the physisorbtion of enflurane was difficult compared to in pure DPPC monolayer. Similarly the physisorbtion was difficult in $n$-hexadecanol monolayer. These results also indicated that the structures of the DHP and DPPC monolayer/water interface were fluidic thus enflurane physisorption occurred.

\section{CONCLUSIONS}

HS-QCM apparatus were sensitive enough to measureme and reveal that anesthetics hydrates physisorbed on the interfacially restricted water formed on a phospholipid monolayers/water interface. Experimental results showed that the physisorption of anesthetic hydrates was influenced not only by the physisorption potency of the anesthetic hydrates but also the form of the interfacially restricted water on the monolayer/water interface. The strength of an anesthetic (anesthetic potency) did not depend only on the type of anesthetics but the structure such as mobility, size, and orientation of molecules at monolayer/water interface were very important factors. In order to obtain better understanding of the anesthesia mechanisms such detail investigations are very important.

\section{ACKNOWLEDGEMENTS}

This work was supported in part by a Grant-in-Aid from the Ministry of Education, Culture, Sports, Science, and Technology (No. 15750118 and 21750143); the NITECH 21 ${ }^{\text {st }}$ Century COE Program "World Ceramics Center for Environmental Harmony", DVA Medical Research and Development Funds, and Grant-in-Aid from the Sakakibara Memorial Hospital Incorporated Foundation.

\section{REFERENCES}

[1] Gennis, R.G. (1990) Molecular structure and function. Biomembrane, Springer, New York.

[2] Gellman, S.H. (1997) Introduction: Molecular recognition. Chemical Reviews, 97, 1231-1232. doi:10.1021/cr970328j

[3] Okamura, Y. and Nakamura, M. (1999) NMR study directly determining drug delivery sites in phospholipid bilayer membrane. The Journal of Physical Chemistry B, 103, 3505-3509. doi:10.1021/jp984621e

[4] Ueda, I. and Yoshida, T. (1999) Hydration of lipid membranes and the action mechanisms of anesthetics and alcohols. Chemistry and Physics of Lipids, 101, 65-79. doi:10.1016/S0009-3084(99)00056-0

[5] Ueda, I. and Yoshida, T. (2002) Interaction of Volatile Anesthetics with Micellar Systems. Encyclopedia of Surface and Colloid Science, Marcel Dekker, Inc., New York, 2607-2613.

[6] Cherkin, A. and Catchpool, J.F. (1964) Temperature de- 
pendence of anesthesia in goldfish. Science, 144, 1460-1462. doi:10.1126/science.144.3625.1460

[7] Flook, V., Adey, G.D., Dundas, C.R. and White, D.C. (1974) Effect of temperature on potency of anesthetic agents. Journal of Applied Physiology, 37, 552-555.

[8] McKenzie, J.D., Calow, P., Clyde, J., Miles, A., Dickinson, R. and Lieb, W.R. (1992) Effect of temperature on the anaesthetic potency of halothane, enflurane and ethanol in daphnia magna (cladocera: crustacea). Comparative Biochemistry and Physiology Part C: Toxicology \& Pharmacology, 101, 15-19. doi:10.1016/0742-8413(92)90193-B

[9] Yoshida, T., Okabayashi, H., Kamaya, H. and Ueda, I. (1989) Stable and unstable binding of a volatile anesthetic enflurane with model lipid vesicle membranes. Biochimca et Biophysica Acta, 979, 287-293. doi:10.1016/0005-2736(89)90246-0

[10] Sauerbrey, G. (1959) Verwendung von schwingquarzen zur wung dner schichten und zur mikrowung. Zeitschrift fur Physik, 155, 206-222. doi:10.1007/BF01337937

[11] Shimazu, K., Yagi, I., Sato, Y. and Uosaki, K. (1992) In situ and dynamic monitoring of the self-assembling and redox processes of a ferrocenylundecanethiol monolayer by electrochemical quartz crystal microbalance. Langmuir, 8, 1385-1387. doi:10.1021/la00041a023

[12] Bruckenstein, S. and Shay, M. (1985) An in situ weighing study of the mechanism for the formation of the adsorbed oxygen monolayer at a gold electrode. Journal of Electroanalytical Chemistry and Interfacial Electrochemistry, 188, 131-136. doi:10.1016/S0022-0728(85)80057-7

[13] Matsuura, N., Elliot, D.J., Furlong, D.N. and Grieser, F. (1997) In situ measurement of lead (II) ion binding to an archidic acid langmuir monolayer using a quartz crystal microbalance. Colloids and Surfaces A: Physicochemical and Engineering Aspects, 126, 189-195. doi:10.1016/S0927-7757(97)00005-8

[14] Aoki, K., Miyamoto, T. and Ohsawa, Y. (1989) The determination of the selectivity coefficient of $\mathrm{Na}+$ versus $\mathrm{Li}+$ on prussian blue thin film in propylene carbonate by means of a quartz crystal microbalance. Bulletin of the Chemical Society of Japan, 62, 1658-1659. doi:10.1246/bcsj.62.1658

[15] Ebara, Y. and Okahata, Y. (1994) A kinetic study of concanavalin: A binding to glycolipid monolayers by using a quartz crystal microbalance. Journal of the American Chemical Society, 116, 11209-11212. doi: $10.1021 / \mathrm{ja} 00104 \mathrm{a} 001$

[16] Sato, T., Serizawa, T., Ohtake, F., Nakamura, M., Terabayashi, T., Kawanishi, Y. and Okahata, Y. (1998) Quantitative measurements of the interaction between monosialoganglioside monolayers and wheat germ agglutinin (WGA) by a quartz crystal microbalance. Biochimca et Biophysica Acta, 1380, 82-92.

[17] Nishino, H., Murakawa, A., Mori, T. and Okahata, Y. (2004) Kinetic studies of AMP-dependent phosphorolysis of amylopectin catalyzed by phosphorylase $b$ on a 27 $\mathrm{MHz}$ quartz-crystal microbalance. Journal of the American Chemical Society, 126, 14752-14757. doi: $10.1021 / \mathrm{ja} 046583 \mathrm{k}$

[18] Hoshino, Y., Kawasaki, T. and Okahata, Y. (2006) Effect of ultrasound on DNA polymerase reactions: Monitoring on a $27-\mathrm{MHz}$ quartz crystal microbalance. Biomacromolecules, 7, 682-685. doi:10.1021/bm050738e

[19] Ebara, Y., Itakukra, K. and Okahata, Y. (1996) Kinetic studies of molecular recognition based on hydrogen bonding at the air-water interface by using a highly sensitive quartz-crystal microbalance. Langmuir, 12, 5165-5170. doi:10.1021/la9603885

[20] Sato, Y., Niwa, O. and Mizutani, F. (2007) Hydrogen bonding interaction between aminopurinthiol-monolayers and oligonucleotides by QCM and XPS measurements. Sensors and Actuators B: Chemical, 121, 214-218. doi:10.1016/j.snb.2006.09.011

[21] Yamamoto, Y., Ando, T., Takayama, M., Egami, T., Ohtsu, Y., Sakurai, A., Yoshida, T., Taga, K., Kamaya, H. and Ueda, I. (2008) Interaction between phospholipid monolayer and volatile anesthetics using quartz crystal oscillator methods. Colloids and Surfaces A: Physicochemical and Engineering Aspects, 317, 568-575. doi:10.1016/j.colsurfa.2007.11.037

[22] Yamamoto, Y., Taga, K., Yoshida, T., Kamaya, H. and Ueda, I. (2006) Action mechanism of water soluble ethanol on phospholipid monolayers using a quartz crystal oscillator. Journal of Colloid and Interface Science, 298, 529-534. doi:10.1016/j.jcis.2005.12.044

[23] Yamamoto, Y., Shervani, Z., Shimoaki, T., Yokoyama, T., Ando, T., Somekawa, A., Takayama, M., Tamaoki, K., Mori, T., Yoshida, T., Taga, K., Kamaya, H. and Ueda, I. (2010) Physisorption behavior of enflurane on the dipalmitoyl phosphatidyl choline (DPPC) monolayer using high sensitive quartz crystal oscillator method. Colloids and Surfaces A: Physicochemical and Engineering Aspects, 367, 47-51. doi:10.1016/j.colsurfa.2010.06.015

[24] Mingotaud, A.F., Mingotaud, C. and Patterson, L.K. (1993) Handbook of monolayers. Academic Press, San Diego.

[25] Seto, N., Mashimo, T., Yoshiya, I. and Taniguchi, Y. (1991) Kyunyumasuiyaku no youkaido-Masuikikoukenkyuu no tameni. Masui-Sosei, 27, 321-324.

[26] Yamamoto, Y., Taga, K., Yoshida, T., Kamaya, H. and Ueda, I. (2006) Temperature dependence of thermodynamic activity in volatile anesthetics: Correlation between anesthetic potency and activity. Journal of Colloid and Interface Science, 301, 488-492. doi:10.1016/j.jcis.2006.05.030

[27] Yoshino, A., Yoshida, T. and Takahashi, K. (1989) ${ }^{2} \mathrm{H}$ NMR study of the behaviour of water in a reversed micellar system: Hydrogen bond breaking and clathrate formation by an inhalation anaesthetic. Magnetic Resonance in Chemistry, 27, 344-347. doi:10.1002/mrc.1260270409

[28] Yoshida, T., Koga, Y., Minowa, H., Kamaya, H. and Ueda, I. (2000) Interfacial lateral electrical conductance on lipid monolayer: Dose-dependent converse effect of alcohols. The Journal of Physical Chemistry B, 104, 1249-1252. doi:10.1021/jp992715y

[29] Fang, A., Haymet, A.D.J., Shinoda, W. and Okazaki, S. (1999) Parallel molecular dynamics simulation: Implementation of PVM for a lipid membrane. Computer Physics Communications, 116, 295-310. doi:10.1016/S0010-4655(98)00089-7 
[30] Okazaki, S. and Ando, Y., (2008) Bunsisimyuresyon de seitaimaku no nazo ni semaru. Kagaku, 63, 25-29.

[31] Makino, M., Kamiya, M., Nakajo, N. and Yoshikawa, K. (1996) Effects of local anesthetics on the dynamic behavior of phospholipid thin film. Langmuir, 12, 4211-4217. doi:10.1021/la950917p

[32] Ebara, Y. and Okahata, Y. (1993) In situ surface-detecting technique by using a quartz-crystal microbalance. Interaction behaviors of proteins onto a phospholipid monolayer at the air-water interface. Langmuir, 9, 574-576. doi:10.1021/la00026a035

[33] Yoshida, T., Takahashi, K., Kamaya, H. and Ueda, I. (1988) ${ }^{19}$ F-NMR study on micellar solubilization of a volatile anesthetic halothane: Dose-related biphasic interaction. Journal of Colloid and Interface Science, 124, 177-185. doi:10.1016/0021-9797(88)90338-4
[34] Yoshida, T., Takahashi, K. and Ueda, I. (1989) Molecular orientation of volatile anesthetics at the binding surface: ${ }^{1} \mathrm{H}$ - and ${ }^{19} \mathrm{~F}-\mathrm{NMR}$ studies of submolecular affinity. Biochimca et Biophysica Acta, 985, 331-333. doi:10.1016/0005-2736(89)90421-5

[35] Yamamoto, Y., Shervani, Z., Ando, T. Takayama, M., Tamaoki, K., Somekawa, A., Yoshida, T., Taga, K. and Ueda, H.K. (Submitted in Colloids and Surfaces A: Physicochemical and Engineering Aspects).

[36] Yoshida, T., Yamamoto, Y., Taga, K., Kamaya, H. Yamamoto, Y., Shervani, Z., Ando, T. Takayama, M., Tamaoki, K., Somekawa, A., Yoshida, T., Taga, K. and Ueda, H.K. Ueda, I. (2003) Effects of water-soluble alcohols on the surface conductance of lipid monolayers: Bimodal action. The Journal of Physical Chemistry B, 107, 3196-3198. doi:10.1021/jp0221845 